\title{
WATER RELATIONS OF CONIFER SEEDLINGS \\ IN DISTURBED VERSUS \\ UNDERSTORY HABITATS
}

A. K. Knapp

W. K. Smith

Botany Department

University of Wyoming

\section{Objectives}

A research project was initiated in the summer of 1980 to study reestablishment of vegetation following prescribed burning in Glacier National Park (GNP), Montana. The problem of conifer re-establishment following disturbance such as fire has often been associated with inadequate moisture conditions (Ronco 1970). The ecophysiological characteristics of a particular species may determine its success in establishment as well as its successional role in a community. Since the goal of prescribed burning is of ten to "set back" succession in a particular community, knowledge of the ecophysiological characteristics of the species involved is vital to the development of sound management policy. Three conifers common to GNP and the Rocky Mountains, Abies lasiocarpa, Picea engelmanni $\mathrm{i}$, and Pinus contorta, were monitored throughout the season to develop baseline information on their water relations at exposed sites, similar to postburn situations, compared to normal understory situations. Although, successional patterns concerning these three conifers have been well documented (Stahelin 1943, Langenheim 1962, Day 1972, Whipple and Dix 1979), their ecophysiological adaptations influencing establishment and succession following a burn or other disturbance has received little attention.

In addition to our measurements on the water relations of conifer seedlings, we have compiled an extensive literature review of conifer succession as well as information on the species composition, abundance, and fuel loading at the proposed prescribed burn sites in GNP.

The data concerning these three conifers will be contrasted with similar data taken for conifers in GNP following the prescribed burns which are scheduled to take place in the spring of 1981: Our plans include monitoring the conifers mentioned as well as the other conifers present at the prescribed burn sites in GNP (Pinus ponderosa, Pseudotsuga menziesii, Larix occidentalis).

We plan to continue ecophysiological studies in GNP to develop a predictive model for the re-establishment of vegetation following prescribed burning, or other disturbances. In addition, environmental measurements during the actual burns will be taken and combined with fuel loading and phytosociological data to evaluate the influence of burn dynamics on vegetation re-establishment. 
Methods

Study sites were located in the Medicine Bow mountains of southeastern Wyoming and were chosen to represent two successional phases in the subalpine zone, saplings of Abies lasiocarpa, Picea engelmanni $i$ and Pinus contorta were monitored in an open (clear-cut) site at $3150 \mathrm{~m}$ elevation and an understory site at $2800 \mathrm{~m}$ beneath a Pinus contorta canopy. Saplings were chosen that grew in close proximity to each other, were 15 to 25 years old and under $2 \mathrm{~m}$ in height. At approximate two week intervals from June 15 to September 1, leaf conductance to water vapor diffusion, $g_{w v}$, xylem water potential, $\psi_{x y l e m}$, and leaf temperature, Tleaf, were measured on sampling days at 2 lemour intervals. Environmental parameters measured concurrently were soil temperature, relative humidity, photosynthetically active radiation, air temperature and soil water potential.

Leaf conductance was measured with a ventilated diffusion porometer designed by Kaufmann and Eckard (1977) and calibrated in the field. One year old needles were used for determinations of $g_{w v}$ : Transpiration flux, J $J_{W v}$, was calculated from $g_{w y}$ and relative humidity and $T$. data. $\psi_{x y l e m}$ was measured with a Schơ ${ }^{2}$ ander-type pressure bomb. Tair was recorded with fine wire (36 ga.) thermocouples and an infra-red field thermometer. Soil temperature and soil water potential were measured with soil thermocouple psychrometers. Relative humidity and solar radiation in the PhAR wavelengths were measured with sensors in the porometer.

Results

Patterns of $g_{w v}$ and $\psi_{x y l e m}$ varied from the open (fig. 1) to the understory environment ( $f i g y$. 2 ) for each of the three conifers. Generally, $g_{\text {wy }}$ was higher in the open site for all three species both diurnally and seasonally. Leaf conductance was usually highest throughout sampling days in Abies lasiocarpa, intermediate in Pinus contorta and lowest in Picea engelmannii. Patterns of $\psi$ indicate that al though $\psi$ was lower in the open site for al three conifers early in the season (June), it was higher in the open later in the season (August). This can be explained by the greater soil moisture stress that developed in the understory site in July and August.

Although T $T_{\text {fof }}$ for the three conifers were similar at the two sites, solar radiation was recorded at higher levels for longer periods of time in the open site and the difference in water vapor concentration from the leaf to air, $\Delta C_{w v}$, was also usually greater for longer periods of time in the open when compared to the understory environment. The combination of these factors, increased solar radiation, $\Delta C_{w V}$ and $g_{w V}$ in the open site are responsible for the greater rates of water loss, $J_{\text {wy }}$, for conifers in the open environment (fig. 3). Any conifer that establishes under, or is subjected to an open environment either from prescribed burning or other disturbance must be able to withstand these increased rates of water loss to survive. 


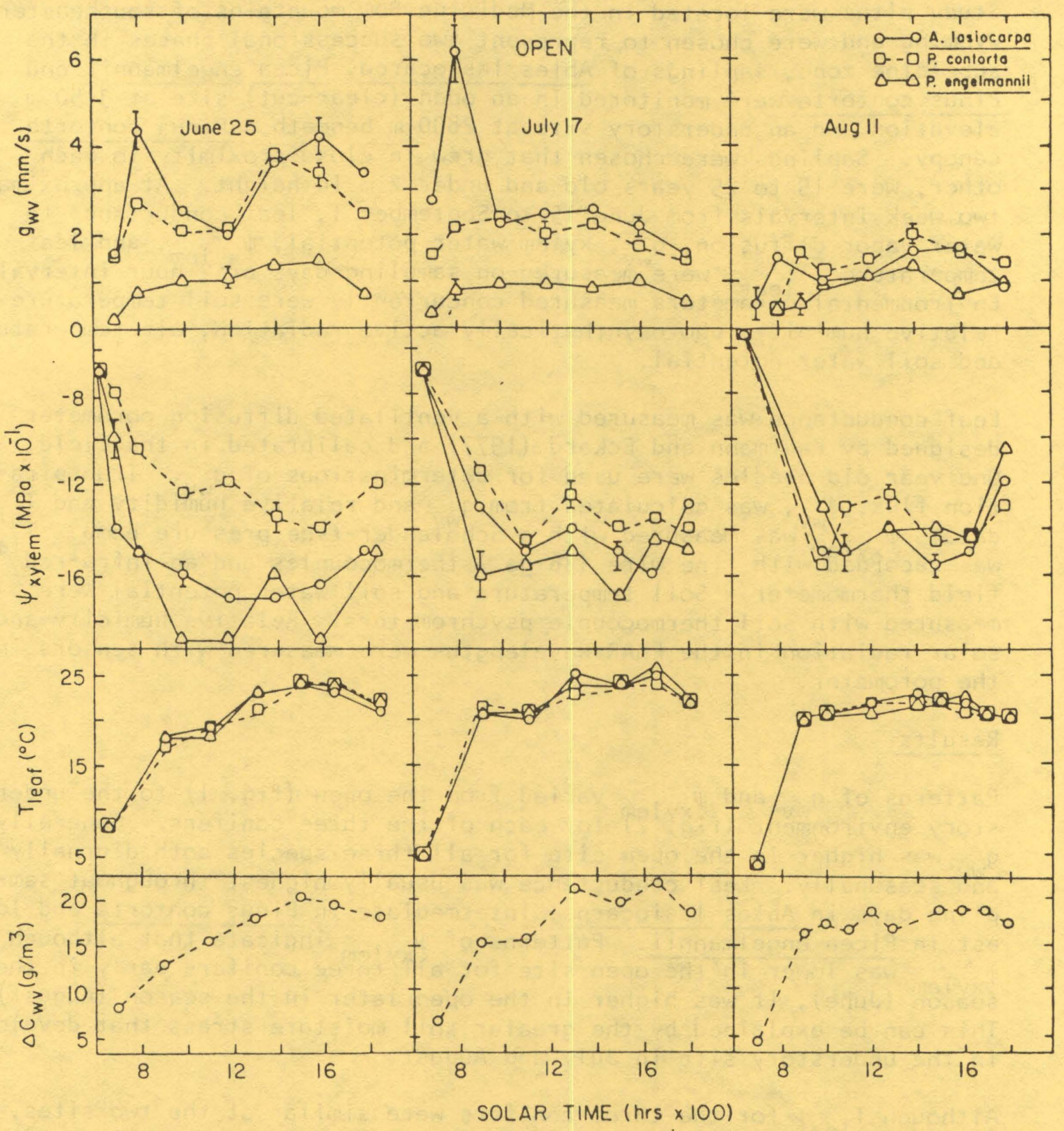

Fig. 1. Seasonal variation in daily patterns of leaf conductance, g $g_{w V}$,

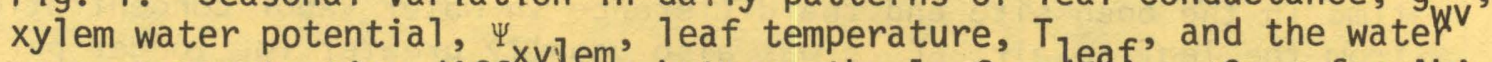
vapor concentration difference between the leaf and aij $r, \Delta C$, for Abies lasiocarpa, Pinus contorta, and Picea engelmannii in the open site. Vertical bars represent \pm 1 standard error from the mean. 


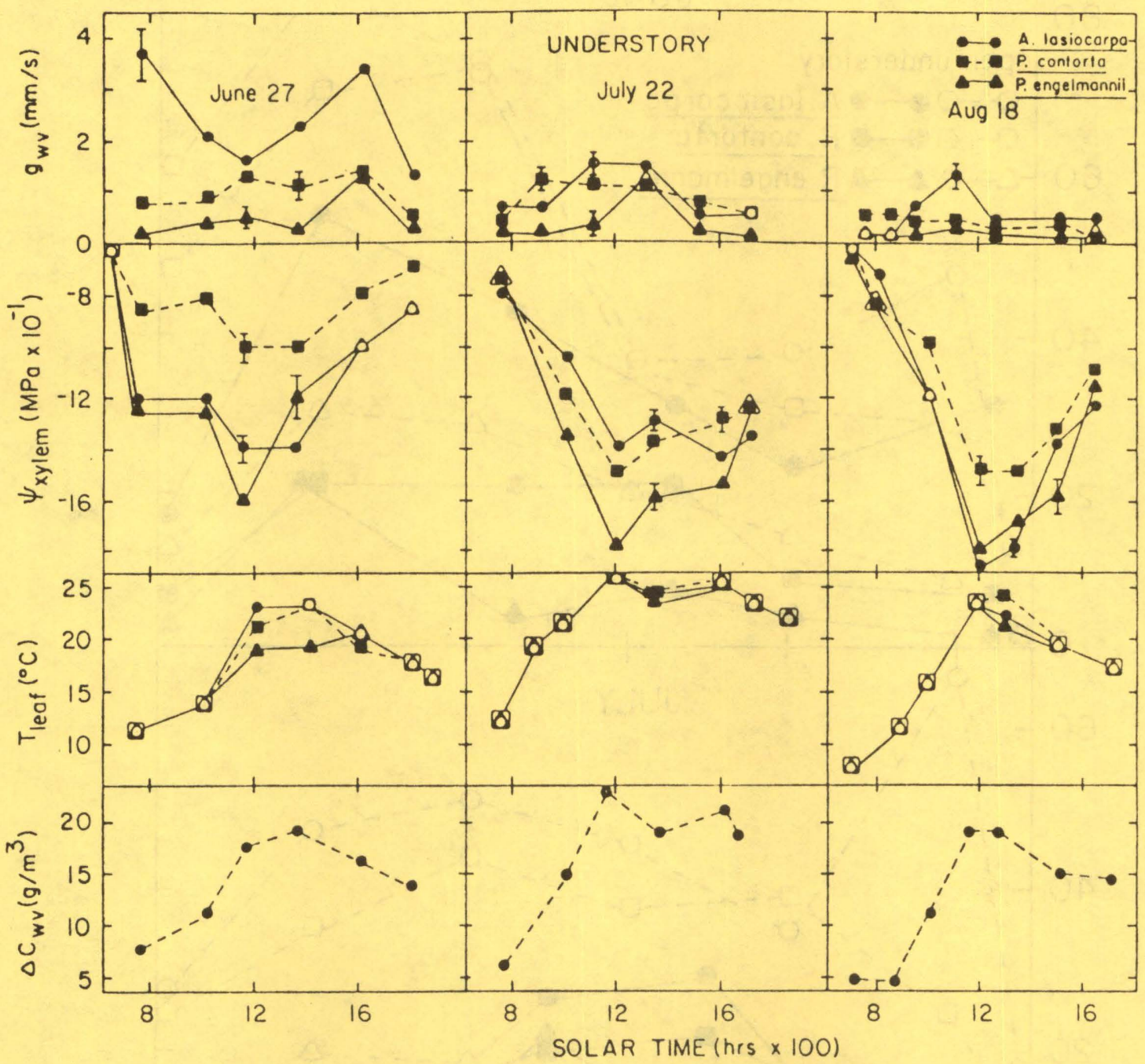

Fig. 2. Seasonal variation in daily patterns of leaf conductance, $g_{w v}$,

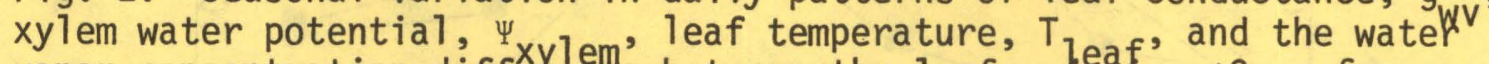
vapor concentration diffextence between the leaf and a f $^{\prime} r, \Delta \mathrm{C}_{w v}$, for Abies lasiocarpa, Pinus contorta, and Picea engelmannii in the understory site. Vertical bars represent \pm 1 standard error from the mean. 


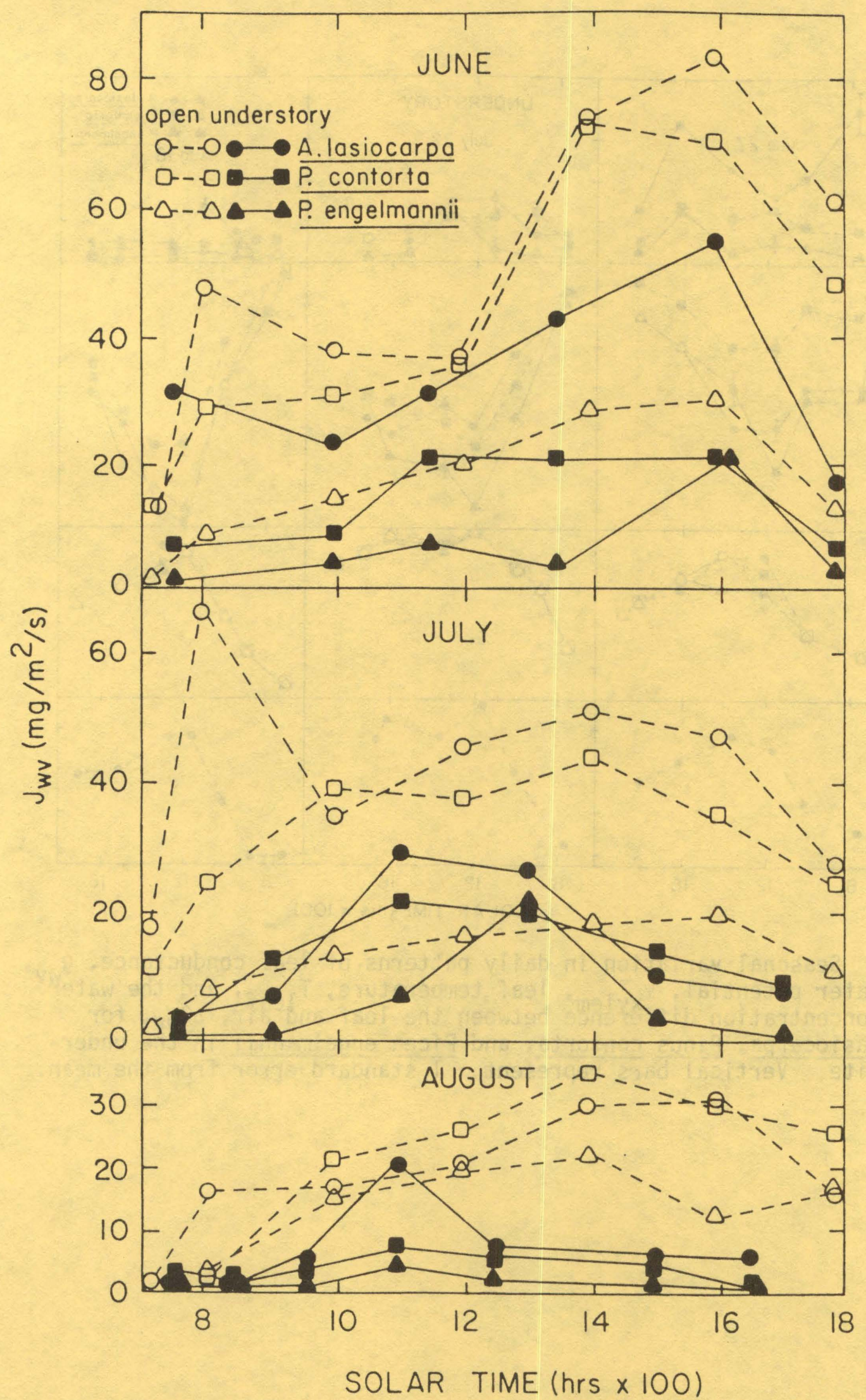

Fig. 3. Daily and seasonal variation in transpiration flux, $J_{\text {wy }}$, from Abies lasiocarpa, Pinus contorta, and Picea engelmannii in the Wopen and understory sites. 
Preliminary data analysis suggest that stomatal control in Pinus contorta is more tightly coupled to avoid internal water stress than the other two conifers and this attribute would increase survival of this conifer in environments with high evaporative demand. Stomatal opening in Picea engelmannii was inversly proportional to levels of $\nabla C_{w v}$ and Abies lasiocarpa appears to be the conifer with the greatest moisture requi rements.

Conclusions

From the preliminary data collected, it is evident that differences in water use patterns among the three conifers may be very important in determining their success in disturbed sites. Continued study of the water relations of the three conifers is planned to develop more precise data that will enable prediction of success or failure of any of the three conifers under environmental conditions that occur either naturally, or due to management practice.

\section{Literature Cited}

Day, R. J. 1972. Stand structure, succession, and use of southern Alberta's Rocky Mountain forest. Ecol. 53:472-478.

Kaufmann, M. R. and A. N. Eckard. 1977. A portable instrument for rapidly measuring conductance and transpiration of conifers and other species. For. Sci. 23:227-237.

Langenheim, J. H. 1962. Vegetation and environmental pattern in the Crested Butte Area, Gunnison County, Co. Ecol. Mono. 32:249-285.

Ronco, F. 1970. Influence of high light intensity on survival of planted Engelmann spruce. For. Sci. 16:331-339.

Stahelin, R. 1943. Factors influencing the natural restocking of high altitude burns by coniferous trees in the central Rocky Mountains. Eco. 24:19-30.

Whipple, S. A. and R. L. Dix. 1979. Age structure and successional dynamics of a Colorado subalpine forest. Amer. Mid. Nat. 101:142-158. 